\title{
Application of Peng-Robinson Equation of State for Calculating Solid-Vapor and Solid-Liquid Equilibrium of $\mathrm{CH}_{4}-\mathrm{CO}_{2}$ System
}

\author{
Gede Wibawa ${ }^{1}$, Muhammad F. A. Nafi ${ }^{1}$, Asti Permatasari ${ }^{1}$ \& Asalil Mustain ${ }^{2}$ \\ 1 Department of Chemical Engineering, Faculty of Industrial Technology, Sepuluh Nopember Institute of \\ Technology (ITS), Kampus ITS Sukolilo, Indonesia \\ ${ }^{2}$ Department of Chemical Engineering, State Polytechnic of Malang, Indonesia \\ Correspondence: Gede Wibawa, Department of Chemical Engineering, Faculty of Industrial Technology, \\ Sepuluh Nopember Institute of Technology (ITS), Kampus ITS Sukolilo, Surabaya 60111, Indonesia. E-mail: \\ gwibawa@chem-eng.its.ac.id
}

Received: May 4, 2015

Accepted: June 5, 2015

Online Published: June 30, 2015

doi:10.5539/mas.v9n7p177

URL: http://dx.doi.org/10.5539/mas.v9n7p177

\begin{abstract}
In this study, the performances of Peng-Robinson Equation of State combined with the classical mixing rules were evaluated to calculate solid-vapor equilibrium (SVE) and solid-liquid equilibrium (SLE) of $\mathrm{CH}_{4}-\mathrm{CO}_{2}$ system. The evaluation was performed by comparing the calculated values with the literature data. In the calculation of SVE, the new binary interaction parameter values $\left(k_{i j}\right)$ of $\mathrm{CH}_{4}-\mathrm{CO}_{2}$ mixtures were proposed in this work based on the experimental data. The proposed $k_{i j}$ obtained in this work might increase the accuracy of Peng-Robinson Equation of State by reducing average absolute deviation in the temperatures between calculated values and literature data from $(2.18 \%$ to $0.26 \%),(0.88 \%$ to $0.70 \%)$ and $(0.61 \%$ to $0.44 \%)$ at $\mathrm{CO}_{2}$ composition of $1 \%, 1.91 \%$ and $2.93 \%$, respectively. Significant improvement was found at $\mathrm{CO}_{2}$ composition of $1 \%$. In the calculation of SLE, new parameters were not proposed since the calculation using the existing (literature) $k_{i j}$ gives good results with an average absolute deviation of $0.5 \%$.
\end{abstract}

Keywords: SVE, SLE, Peng-Robinson Equation of State, methane, carbon dioxide

\section{Introduction}

The increasing number of population and technology advancement encourages the world's rising energy consumption. One of the widely used energy is natural gas. The advantages of the using natural gas compared to other energy sources are energy generated from natural gas is more efficient, cleaner, and environmentally friendly. In addition, natural gas is also colorless, odorless, non-toxic, and non-corrosive (van Egteren, 1993). The composition of raw natural gas is depending on the reservoir source location. It is generally containing of $30 \%$ to $90 \%$ methane, with other light hydrocarbons (i.e., ethane, propane and other heavier hydrocarbons). On the other hand, some contaminants, such as water, carbon dioxide $\left(\mathrm{CO}_{2}\right)$, hydrogen sulfide, helium and nitrogen, are also contained in the natural gas (Scholes et al., 2012). $\mathrm{CO}_{2}$ is one of greenhouse gas that causes global warming. $\mathrm{CO}_{2}$ is also an acidic gas and reacts with water to form acidic compounds, namely strong carbonic acid $\left(\mathrm{H}_{2} \mathrm{CO}_{3}\right)$ which can cause corrosion in piping systems.

Recently, there are so many methods to distribute natural gas. One of the promising methods used in the distribution of natural gas is liquefied natural gas (LNG). By using this method, the volume of natural gas can be reduced significantly after the liquefaction process that can make the natural gas transportation more efficient (Stringari et al., 2014). In the production of LNG, $\mathrm{CO}_{2}$ must be removed from natural gas. One of $\mathrm{CO}_{2}$ removal technology is controlled freeze out method. In this method, $\mathrm{CO}_{2}$ is removed by utilizing behaviour of phase transitions among vapor, liquid and solid phases. To rational design and optimization condition of this type of separation method, solid-vapor equilibrium (SVE) and solid-liquid equilibrium (SLE) of $\mathrm{CH}_{4}-\mathrm{CO}_{2}$ system are necessary. In this work, The performance of Peng-Robinson Equation of State (Peng and Robinson, 1976) combined with the classical mixing rules in calculating phase equilibrium for SVE and SLE of $\mathrm{CH}_{4}-\mathrm{CO}_{2}$ system was evaluated.

\section{Calculation Method}

In this work, the standard form of Peng-Robinson Equation of State (PR-EoS) was used for the prediction of 
solid-vapor and solid-liquid equilibrium for binary mixtures of $\mathrm{CH}_{4}-\mathrm{CO}_{2}$ :

$$
P=\frac{R T}{V-b_{m}}-\frac{a_{m}}{V\left(V+b_{m}\right)+b_{m}\left(V-b_{m}\right)}
$$

Eq. (1) in cubic form can be written as the following form:

$$
Z^{3}-(1-B) Z^{2}+\left(A-3 B^{2}-2 B\right) Z-\left(A B-B^{2}-B^{3}\right)=0
$$

where

$$
\begin{aligned}
& A=\frac{a_{m} P}{R^{2} T^{2}} \\
& B=\frac{b_{m} P}{R T}
\end{aligned}
$$

The values of $a_{\mathrm{m}}$ and $b_{m}$ of the mixtures were calculated using the classical mixing rules to apply PR-EoS to the mixtures based on the following description:

$$
\begin{gathered}
a_{m}=\sum_{i=1}^{N} \sum_{j=1}^{N} z_{i} z_{j}\left(a_{i} a_{j}\right)^{0.5}\left(1-k_{i j}\right) \\
b_{m}=\sum_{i=1}^{N} z_{i} b_{i} \\
a_{i}=0.45274 \frac{R^{2} T_{c i}^{2}}{P_{c i}}\left[1+m_{i}\left(1-\left(\frac{T}{T_{c i}}\right)^{0.5}\right)\right]^{2} \\
b_{i}=0.0778 \frac{R T_{c i}}{P_{c i}} \\
m_{i}=0.37464+1.54226 \omega_{i}-0.26992 \omega_{i}^{2}
\end{gathered}
$$

where $z_{i}$ are the mole fraction of component $i, \omega_{\mathrm{i}}$ are the accentric factor of component $i$ and $k_{i j}$ are the binary interaction parameter characterizing molecular interactions between molecules $i$ and $j$.

\subsection{Solid-Vapor Equilibrium}

The fugacity coefficient of a component in the mixture can be calculated using PR-EoS by the following equation:

$$
\varphi_{i}=\exp \left(\frac{b_{i}}{b_{m}}(Z-1)-\ln (Z-B)-\frac{A}{2 \sqrt{2} B}\left(\frac{2 \sum_{j} z_{j}\left(a_{i} a_{j}\right)^{0.5}\left(1-k_{i j}\right)}{a_{m}}-\frac{b_{i}}{b_{m}}\right) \ln \left(\frac{Z+(1+\sqrt{2}) B}{Z+(1-\sqrt{2}) B}\right)\right)
$$

Due to the solid phase is almost containing of $\mathrm{CO}_{2}$ only, the assumption of pure solid $\mathrm{CO}_{2}$ formation was used. So, the equilibrium relationship between solid and vapor phase in the $\mathrm{CO}_{2}$ freezing phenomena can be described below:

$$
x_{2} \varphi_{2}^{v} P=P_{2 \text { Solid }}^{\text {sat }} \varphi_{2}^{\text {sat }} \exp \left(\frac{V_{2 \text { Solid }}\left(P-P_{2 \text { solid }}^{\text {sat }}\right)}{R T}\right)
$$

The $\mathrm{CO}_{2}$ vapor pressure was calculated using the exponential equation as described below:

$$
P_{2 \text { solid }}^{\text {sat }}=9.44 \cdot 10^{8} \exp \left(-\frac{3108.2}{T}\right)
$$

Although Eq. (11) derived from equating partial fugacity describes the necessary condition for solid $\mathrm{CO}_{2}$ formation, but it is not sufficient to show the stability of the produced solids. So, the following condition should also be checked in this case: 


$$
T \leq T^{T P}
$$

where $T^{T P}$ is the triple point temperature (for $\mathrm{CO}_{2}, T^{T P}=216.55 \mathrm{~K}$ ). There are several cases where solids formation is thermodynamically predicted, but the temperature is too high for a stable solid (ZareNezhad and Eggeman, 2006).

\subsection{Solid-Liquid Equilibrium}

The fugacity coefficient of a component in the mixture can be calculated using PR-EoS by the following equation:

$$
\varphi_{i}=\exp \left(\frac{b_{i}}{b_{m}}(Z-1)-\ln (Z-B)-\frac{A}{2 \sqrt{2} B}\left(\frac{2 \sum_{j} z_{j}\left(a_{i} a_{j}\right)^{0.5}\left(1-k_{i j}\right)}{a_{m}}-\frac{b_{i}}{b_{m}}\right) \ln \left(\frac{Z+(1+\sqrt{2}) B}{Z+(1-\sqrt{2}) B}\right)\right)
$$

Assuming solid phase is pure $\mathrm{CO}_{2}$, the solubility of solid $\mathrm{CO}_{2}$ (2) in the $\mathrm{CH}_{4}$ (1) can be described by the following equilibrium relationship:

$$
x_{2} \varphi_{2}^{l} P=P_{2 \text { solid }}^{\text {sat }} \varphi_{2}^{\text {sat }} \exp \left(\frac{V_{2 \text { Solid }}\left(P-P_{2 \text { Solid }}^{\text {sat }}\right)}{R T}\right)
$$

To find the solubility of $\mathrm{CO}_{2}$, Eq. (15) can be simplified into the following equation (Shen et al., 2012):

$$
x_{2}=\frac{P_{2 \text { solid }}^{\text {sat }} \varphi_{2}^{\text {sat }} \exp \left(\frac{V_{2 \text { Solid }}\left(P-P_{2 \text { Solid }}^{\text {sat }}\right)}{R T}\right)}{\varphi_{2}^{l} P}
$$

\section{Results and Discussion}

In this work, the calculation of frost points have been made using PR-EoS for the binary $\mathrm{CH}_{4}-\mathrm{CO}_{2}$ system with the $\mathrm{CO}_{2}$ compositions of $1 \% ; 1.91 \%$; and $2.93 \%$. The results were compared with the experimental data determined by Le and Trebble (2007). The best fitted binary interaction parameters based on the classical mixing rule of PR-EoS obtained in this work for the calculation of SVE of $\mathrm{CH}_{4}-\mathrm{CO}_{2}$ system are presented in Table 1 together with the literature $k_{i j}$ data as comparison.

Table 1. The best fitted binary interaction parameters obtained in this work for $\mathrm{SVE}$ of $\mathrm{CH}_{4}-\mathrm{CO}_{2}$ system

\begin{tabular}{ccc}
\hline $\mathrm{CO}_{2}$ Composition & \multicolumn{3}{c}{$k_{i j}$} \\
\cline { 2 - 3 } & ZareNezhad and Eggeman, 2006 & This Work \\
\hline $1 \%$ & $-36.134 / \mathrm{T}^{2}+5.4835 / \mathrm{T}+0.0998$ & $-5 \cdot 10^{-7} / \mathrm{T}^{2}-6 \cdot 10^{-9} / \mathrm{T}+0.6344$ \\
$1.91 \%$ & $-36.134 / \mathrm{T}^{2}+5.4835 / \mathrm{T}+0.0998$ & $-23220 / \mathrm{T}^{2}+270.84 / \mathrm{T}-0.6691$ \\
$2.93 \%$ & $-36.134 / \mathrm{T}^{2}+5.4835 / \mathrm{T}+0.0998$ & $-45967 / \mathrm{T}^{2}+521.46 / \mathrm{T}-1.3487$ \\
\hline
\end{tabular}

The frost points calculated using the binary interaction parameters obtained in this work and using those obtained by ZareNezhad and Eggeman (2006) were compared with the experimental data (Le and Trebble, 2007) as shown in Table 2. As shown in this table, the significant improvement of accuracy was found for $\mathrm{CO}_{2}$ concentration of $1 \%$ by reducing AAD from $\left(2.18 \%\right.$ to $0.26 \%$ ). However for other $\mathrm{CO}_{2}$ concentrations studied, the improvements were not significant because the calculation using existing $k_{i j}$ also gave a little bit same magnitude of errors with the experimental data. In addition, the proposed present $k_{i j}$ values in this work gave high accuracy for the correlation at lower $\mathrm{CO}_{2}$ concentration. The illustrations of the improvements were presented in Figures 1 to 3. 
Table 2. Average absolute deviation between calculated and experimental (Le and Trebble, 2007) frost point data using present and literature $k_{i j}$ for $\mathrm{SVE}$ of $\mathrm{CH}_{4}-\mathrm{CO}_{2}$ system

\begin{tabular}{ccc}
\hline $\mathrm{CO}_{2}$ Composition & \multicolumn{3}{c}{$A A D(\%)$} \\
\cline { 2 - 3 } & ZareNezhad and Enggeman, 2006 & This Work \\
\hline $1 \%$ & 2.18 & 0.26 \\
$1.91 \%$ & 0.88 & 0.70 \\
$2.93 \%$ & 0.61 & 0.44 \\
\hline
\end{tabular}

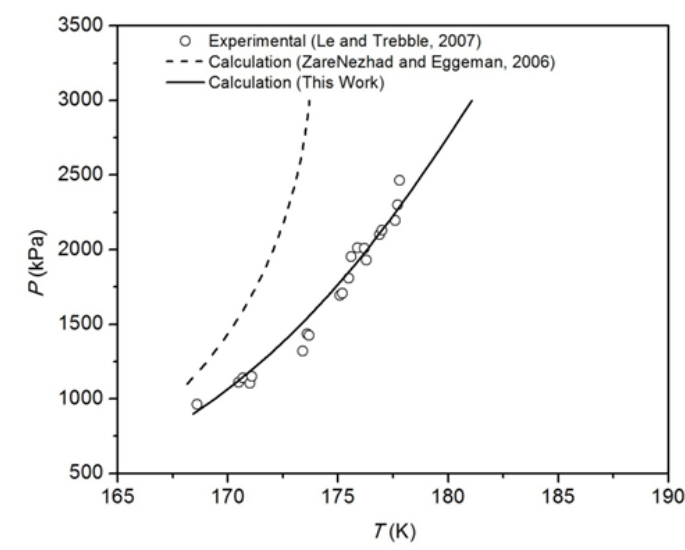

Figure 1. Comparison of calculated frost points using present and literature $k_{i j}$ with experimental data (Le and Trebble, 2007) for SVE of $\mathrm{CH}_{4}(1)+\mathrm{CO}_{2}(2)$ system for $x_{2}=1 \%$

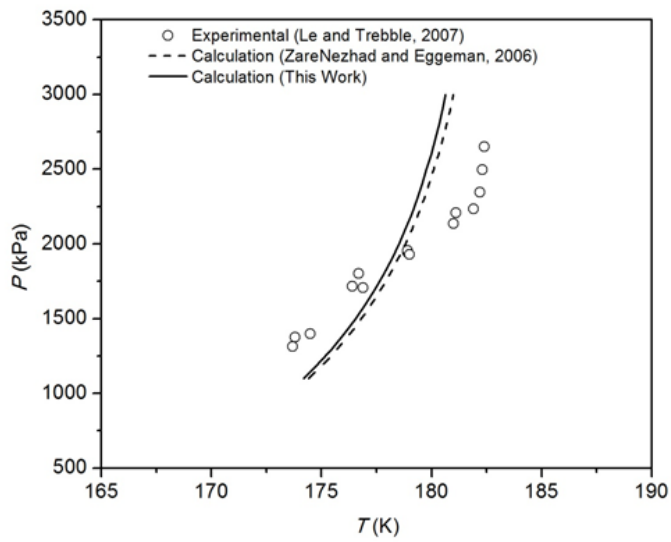

Figure 2. Comparison of calculated frost points using present and literature $k_{i j}$ with experimental data (Le and Trebble, 2007) for $\mathrm{SVE}$ of $\mathrm{CH}_{4}(1)+\mathrm{CO}_{2}(2)$ system for $x_{2}=1.91 \%$

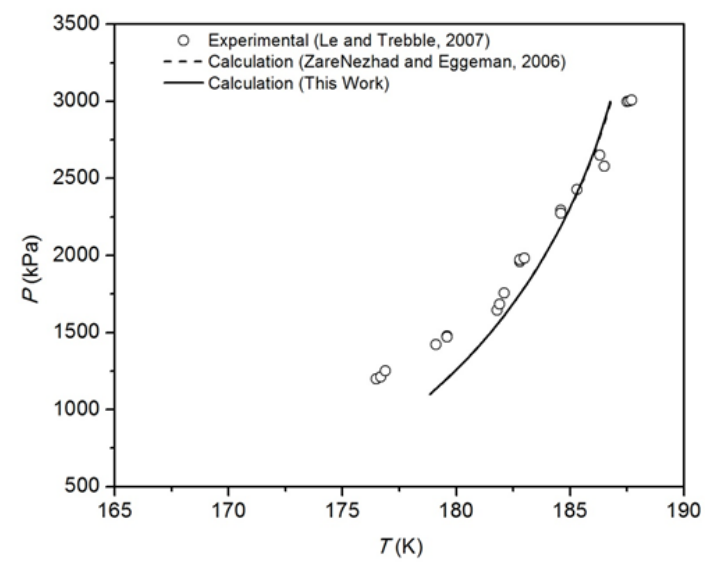

Figure 3. Comparison of calculated frost points using present and literature $k_{i j}$ with experimental data (Le and Trebble, 2007) for SVE of $\mathrm{CH}_{4}(1)+\mathrm{CO}_{2}(2)$ system for $x_{2}=2.93 \%$ 
PR-EoS was also applied to calculate SLE in term of solubility of $\mathrm{CO}_{2}\left(x_{2}\right)$ for $\mathrm{CH}_{4}(1)+\mathrm{CO}_{2}(2)$ system with $k_{i j}$ proposed by ZareNezhad and Eggeman (2006). The results were compared with the experimental data obtained by Shen et al. (2012) and giving a good accuracy with average absolute deviation of $0.5 \%$ between calculated and experimental solubility data. The comparison was presented in Figure 4.

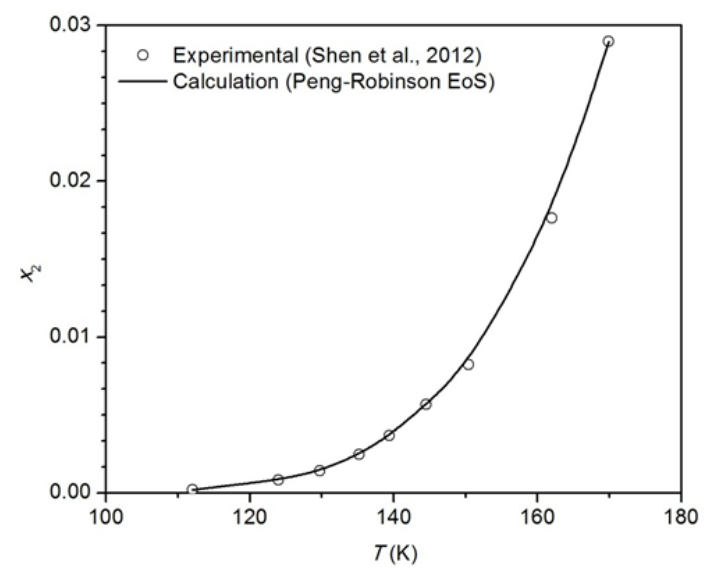

Figure 4. Comparison between calculated solubility of $\mathrm{CO}_{2}(2)$ in $\mathrm{CH}_{4}(1)$ using the Peng-Robinson Equation of State and experimental data obtained by Shen et al. (2012)

\section{Conclusion}

The proposed $k_{i j}$ obtained in this work might improve the accuracy of Peng-Robinson Equation of State combined with classical mixing rules in calculation of SVE of $\mathrm{CH}_{4}(1)+\mathrm{CO}_{2}(2)$ system by reducing average absolute deviation (AAD) from $(2.18 \%$ to $0.26 \%)$ for the $\mathrm{CO}_{2}$ composition of $1 \%,(0.88 \%$ to $0.70 \%)$ for the $\mathrm{CO}_{2}$ composition of $1.91 \%$, and $(0.61 \%$ to $0.44 \%)$ for the $\mathrm{CO}_{2}$ composition of $2.93 \%$. The significant improvement was found for $\mathrm{CO}_{2}$ concentration of $1 \%$. The calculation of SLE based in the literature $k_{i j}$ gave absolute average deviation of $0.5 \%$ between calculated and literature data for solubility of $\mathrm{CO}_{2}$ in $\mathrm{CH}_{4}-\mathrm{CO}_{2}$ system.

\section{Nomenclature}

A Peng-Robinson Equation of State parameter

a Peng-Robinson Equation of State parameter

$B \quad$ Peng-Robinson Equation of State parameter

$b \quad$ Peng-Robinson Equation of State parameter

$k \quad$ Binary interaction coefficient

$m \quad$ Peng-Robinson Equation of State parameter

$N \quad$ Number of component

$P \quad$ System pressure $(\mathrm{kPa})$

$P_{2}^{\text {sat }} \quad$ Saturated vapor pressure of solid $\mathrm{CO}_{2}$ at system temperature $(\mathrm{kPa})$

$R \quad$ Universal gas constant $\left(=8.314 \mathrm{~J} \cdot \mathrm{mol}^{-1} \cdot \mathrm{K}^{-1}\right)$

$T \quad$ System temperature $(\mathrm{K})$

$V \quad$ Molar volume $\left(\mathrm{m}^{3} \cdot \mathrm{mol}^{-1}\right)$

$z \quad$ Mole fraction of component

Z Compressibility factor

Greek letters

$\varphi \quad$ Fugacity coefficient

$\omega \quad$ Acentric factor

Subscripts

c Critical condition 
$i \quad$ Component $i$

$j \quad$ Component $j$

$m \quad$ Mixtures

1 Methane

2 Carbon dioxide

Superscripts

$v \quad$ Vapor phase

$l \quad$ Liquid phase

sat Saturated condition

TP Triple point

\section{References}

Le, T. T., \& Trebble, M. A. (2007). Measurement of carbon dioxide freezing in mixtures of methane, ethane, and nitrogen in the solid-vapor equilibrium region. Journal of Chemical \& Engineering Data, 52, 683-686. http://dx.doi.org/10.1021/je060194j

Peng, D. Y., \& Robinson, D. B. (1976). A new two-constant equation of state. Industrial \& Engineering Chemistry Fundamentals, 15, 59-64. http://dx.doi.org/10.1021/i160057a011

Scholes, C. A., Stevens, G. W., \& Kentish, S. E. (2012). Membrane gas separation applications in natural gas processing. Fuel, 96, 15-28. http://dx.doi.org/10.1016/j.fuel.2011.12.074

Shen, T., Gao, T., Lin, W., \& Gu, A. (2012). Determination of $\mathrm{CO}_{2}$ solubility in saturated liquid $\mathrm{CH}_{4}+\mathrm{N}_{2}$ and $\mathrm{CH}_{4}+\mathrm{C}_{2} \mathrm{H}_{6}$ mixtures above atmospheric pressure. Journal of Chemical \& Engineering Data, 57, 2296-2303. http://dx.doi.org/10.1021/je3002859

Stringari, P., Campestrini, M., Coquelet, C., \& Arpentinier, P. (2014). An equation of state for solid-liquid-vapor equilibrium applied to gas processing and natural gas liquefaction. Fluid Phase Equilibria, 362, 258-267. http://dx.doi.org/10.1016/j.fluid.2013.10.020

van Egteren, M. (1993). Natural gas for electric power generation: Advantages, availability and reliability. Utilities Policy, 3, 145-153. http://dx.doi.org/10.1016/0957-1787(93)90006-I

ZareNezhad, B., \& Eggeman, T. (2006). Application of Peng-Rabinson Equation of State for $\mathrm{CO}_{2}$ freezing prediction of hydrocarbon mixtures at cryogenic conditions of gas plants. Cryogenics, 46, 840-845. http://dx.doi.org/10.1016/j.cryogenics.2006.07.010

\section{Copyrights}

Copyright for this article is retained by the author(s), with first publication rights granted to the journal.

This is an open-access article distributed under the terms and conditions of the Creative Commons Attribution license (http://creativecommons.org/licenses/by/3.0/). 